\title{
Highly biocompatible, nanocrystalline hydroxyapatite synthesized in a solvothermal process driven by high energy density microwave radiation
}

\author{
This article was published in the following Dove Press journal: \\ International Journal of Nanomedicine \\ II February 2013 \\ Number of times this article has been viewed
}

\section{Dariusz Smolen' \\ Tadeusz Chudoba' \\ Iwona Malkal \\ Aleksandra Kedzierska' \\ Witold Lojkowski' \\ Wojciech Swieszkowski \\ Krzysztof Jan Kurzydlowski \\ Małgorzata Kolodziejczyk- \\ Mierzynska ${ }^{3}$ \\ Małgorzata Lewandowska- \\ Szumiel $^{3}$ \\ 'Polish Academy of Science, Institute of High Pressure Physics, Warsaw, \\ Poland; ${ }^{2}$ Faculty of Materials \\ Engineering, Warsaw University \\ of Technology, Warsaw, Poland; \\ ${ }^{3}$ Department of Histology and Embryology, Center of Biostructure Research, Medical University of Warsaw, Warsaw, Poland}

Correspondence: Dariusz Smolen Institute of High Pressure Physics PAS, Sokolowska 29/37,

0I-142 Warsaw, Poland

Tel +48228760316

Fax +48226324218

Email smolendarek@gmail.com

\begin{abstract}
A microwave, solvothermal synthesis of highly biocompatible hydroxyapatite (HAp) nanopowder was developed. The process was conducted in a microwave radiation field having a high energy density of $5 \mathrm{~W} / \mathrm{mL}$ and over a time less than 2 minutes. The sample measurements included: powder X-ray diffraction, density, specific surface area, and chemical composition. The morphology and structure were investigated by scanning electron microscopy as well as transmission electron microscopy (TEM). The thermal behavior analysis was conducted using a simultaneous thermal analysis technique coupled with quadruple mass spectrometry. Additionally, Fourier transform infrared spectroscopy tests of heated samples were performed. A degradation test and a biocompatibility study in vitro using human osteoblast cells were also conducted. The developed method enables the synthesis of pure, fully crystalline hexagonal HAp nanopowder with a specific surface area close to $240 \mathrm{~m}^{2} / \mathrm{g}$ and a Ca/P molar ratio equal to 1.57 . TEM measurements showed that this method results in particles with an average grain size below $6 \mathrm{~nm}$. A 28-day degradation test conducted according to the ISO standard indicated a $22 \%$ loss of initial weight and a calcium ion concentration at $200 \mu \mathrm{mol} / \mathrm{dm}^{3}$ in the tris(hydroxymethyl)aminomethane hydrochloride test solution. The cytocompatibility of the obtained material was confirmed in a culture of human bone derived cells, both in an indirect test using the material extract, and in direct contact. A quantitative analysis was based on the 2,3-bis-(2-methoxy-4-nitro-5-sulfophenyl)-2H-tetrazolium5-carboxanilide. Viability assay as well as on DNA content measurements in the PicoGreen test. Indirect observations were performed at one point in time according to the ISO standard for in vitro cytotoxicity (ie, after 24 hours of cell exposure to the extracts). The direct contact tests were completed at three time points: after 24 hours, on day 7, and on day 14 of a culture in an osteogenic medium. All of the tests revealed good tolerance of cells toward the material; this was also shown by means of live/dead fluorescent staining. Both quantitative results and morphological observations revealed much better cell tolerance toward the obtained HAp compared to commercially available HAp NanoXIM, which was used as a reference material.
\end{abstract}

Keywords: bone regeneration, bone substitute, microwave, HAp

\section{Introduction}

Resorbable, bone-compatible materials are required for construction of tissueengineered bone products which are used when a significant amount of new bone regeneration is required. These cases include severe bone fractures resulting from traumatic injury, fusion repair, void filling following the removal of bone tumors, and several dental indications. The last few years have seen a rapid increase in the number of cases in which bone defects required replacement, with most causes due 
to cancer and aging. ${ }^{1,2}$ The current clinical gold standard for bone replacement therapy is an autograft, which provides the primary factors for effective bone regeneration: osteoconductivity, osteoinductivity, and osteogenesis. However, autografts impose a significant cost and risk for the patient with the need for double surgery. ${ }^{3}$

Advances in synthetic bone graft substitutes are playing an increasingly important role in large bone defects and gap healing, as they are potentially able to overcome the disadvantages of current medical practices. The primary purpose of tissue-engineered resorbable implants is to induce the natural bone healing process, which otherwise would not occur over critical-sized defects. A major challenge in the development of resorbable bone substitutes is the possibility of providing a material with both good initial mechanical stability as well as fast osteointegration and resorption after implantation. Most of these requirements are satisfied by scaffolds made of hydroxyl acids, such as polylactic acid or poly(lacticco-glycolic acid); however, despite their good mechanical properties, low toxicity, and predictable biodegradation kinetics, these materials do not provide a proper surface for cell attachment and proliferation due to the lack of specific cell-recognizable signals. ${ }^{4}$

Bioactive ceramics as a material for bone implants have appropriate osteoconductivity and biocompatibility due to their chemical and structural similarity to the mineral phase of native bone. In addition, the interactions of osteogenic cells with these ceramics lead to good bone bonding ability and bone regeneration..$^{5-7}$ The most commonly used ceramic materials are various grafts made of submicron hydroxyapatite (HAp), calcium phosphate, and bio-glasses, which are all in the form of particles, powders, paste, or granules. They are suitable for small bone gaps.

On the other hand, for the healing of large bone gaps, biocompatible material with a high resorption rate and good mechanical properties is required. Calcium deficient HAp may play an important role as a material satisfying these requirements. ${ }^{8}$ Chemical properties such as ion exchange or the degradation rate in solution are strongly dependent on the $\mathrm{Ca} / \mathrm{P}$ ratio. Natural apatite crystals have a calcium deficiency $\mathrm{Ca} / \mathrm{P}$ ratio near 1.5 , which is close to tricalcium phosphate stoichiometry, but, structurally and chemically, it is similar to stoichiometric HAp with $\mathrm{Ca} / \mathrm{P}$ equal to $1.67 .8,9$ Nonstoichiometric HAp in comparison to synthetic stoichiometric HAp has a higher solubility and degradation rate, and additionally these parameters increase with a decrease in the HAp Ca/P molar ratio. ${ }^{9}$ The first step towards the development of such material is to produce nanoparticles that will serve as building blocks for the future bio-nanomaterial for bone regrowth scaffold.

In addition to nonstoichiometry, particle size may also determine the material resorption rate and its bioactivity. ${ }^{10,11}$ The high value of the specific surface area (SSA) to volume ratio may significantly increase the material solubility, which is important for achieving resorbable scaffolds. ${ }^{11}$ Additionally, a decrease in the material grain size improves the osteoblast adhesion to the implant surface. ${ }^{12}$

Many papers have described the HAp synthesis process. ${ }^{13-16}$ One popular method is solvothermal synthesis that is conducted in mills. ${ }^{13}$ This process enables achievement of HAp with an average grain size close to $20 \mathrm{~nm}$, and a surface as measured by the Brunauer-Emmett-Teller (BET) technique around $140 \mathrm{~m}^{2} / \mathrm{g}$. Due to the additional substrates used during this process, usually the obtained HAp will have a high number of extra ions such as sodium cations or carboxyl anions, and typically the $\mathrm{Ca} / \mathrm{P}$ stoichiometry is close to 1.67. In some papers the authors have presented the possibility of nonstoichiometric HAp synthesis with the use of mills, which allows us to obtain spherical HAp particles with a width grain size distribution. ${ }^{14}$

Microwave energy has also been used a few times as a source of energy in HAp synthesis, although not in closedpressure systems with very high energy density. Traditional microwave heating allows the synthesis of spherical and needle-like shapes, with the lowest average size of $5 \times 15 \mathrm{~nm}$ and stoichiometry mostly close to $1.67 .{ }^{15}$

Several papers have presented the synthesis of HAp with very large surface areas, even close to $300 \mathrm{~m}^{2} / \mathrm{g}$. In these cases the authors did not achieve pure HAp, but synthesized a product mix of HAp with surface active substrates and unreacted organic additions. ${ }^{16}$

Various processes have been developed to prepare nanosized apatite powders. ${ }^{13-16}$ Within these studies there appears to be a lack of simple synthesis methods which would result in a fully crystalline calcium deficient HAp nanopowder with a hexagonal structure, a grain size much below $10 \mathrm{~nm}$, and a surface area greater than $200 \mathrm{~m}^{2} / \mathrm{g}$.

One potential solution is to drive the reactions with microwave radiation, as this is able to homogenously and rapidly heat the entire volume of the vessel almost without a temperature gradient in the heated materials. Microwave radiation is able to provide heat to a reaction solution much more efficiently than conventional reactions. ${ }^{17,18}$ This method has other advantages such as fast reaction, high yield, excellent reproducibility, a narrow particle size distribution, and high purity. ${ }^{19,20}$ 
The purpose of this work was to obtain HAp nanopowder that provides a degradation rate and biological properties much greater than the currently available HAp powders. This paper reports on the synthesis of HAp nanopowder using a solvothermal reaction with microwave heating. The novelty of this method lies in the extremely short synthesis time, in the range of 90 seconds. This short time is made possible by the use of a special reactor with a high microwave energy density reaching $5 \mathrm{~W} / \mathrm{mL}$ in a water solution, thereby ensuring a nonequilibrium nanostructure of HAp. The paper presents the chemical, physical, and biological properties of the obtained material, including the chemical composition, structure and morphology, solubility, and biocompatibility.

\section{Materials and methods Preparation of HAp nanoparticles}

The HAp nanocrystals were obtained by the following method. ${ }^{21}$ The starting materials used for the HAp synthesis were calcium hydroxide $\left(\mathrm{Ca}[\mathrm{OH}]_{2}\right.$, pure; CHEMPUR, Piekary Slaskie, Poland) and phosphoric acid $\left(\mathrm{H}_{3} \mathrm{PO}_{4}, 85 \%\right.$ solution, pure for analysis; CHEMPUR); the reactants were used in a molar ratio $\mathrm{Ca} / \mathrm{P}$ of 1.67 . To form a reaction solution, phosphoric acid was added drop-wise to the calcium solution at a rate of $0.01 \mathrm{~mL}$ every 3 seconds, and the solution was intensively stirred at room temperature. After 30 minutes of additional stirring, the reaction solution was transferred into a capped Teflon vessel and heated using microwave radiation. The microwave reactor was produced by ERTEC (Wroclaw, Poland) and was operated at $2.45 \mathrm{GHz}$ and at a power density adjusted to $5 \mathrm{~W} / \mathrm{mL}$. The time, pressure, and microwave power were computer controlled. The synthesis conditions were $1 \mathrm{MPa}$ pressure over 90 seconds. After the synthesis, the obtained powder was washed by anhydrous ethanol and dried in an air flow at a temperature of $30^{\circ} \mathrm{C}$ for 16 hours. Herein, this resulting material is referred to as "GoHAP."

The HAp nanopowder NanoXIM201 (Fluidinova, Moreira da Maia, Portugal) was used as a reference material in the degradation and biocompatibility tests. To the authors' knowledge, this commercially available HAp powder had the lowest available particle size on the market. Its characteristics were: a density of $2.93 \mathrm{~g} / \mathrm{dm}^{3}$, an SSA of $120 \mathrm{~m}^{2} / \mathrm{g}$, an average particle diameter calculated from SSA of $17 \mathrm{~nm}$, and a $\mathrm{Ca} / \mathrm{P}$ molar ratio as declared by the producer and confirmed by the authors of 1.66 . Figure 1 shows a scanning electron microscopy (SEM) micrograph of NanoXIM201 nanopowder, showing an average grain size around $20 \mathrm{~nm}$ aggregated in micrometer

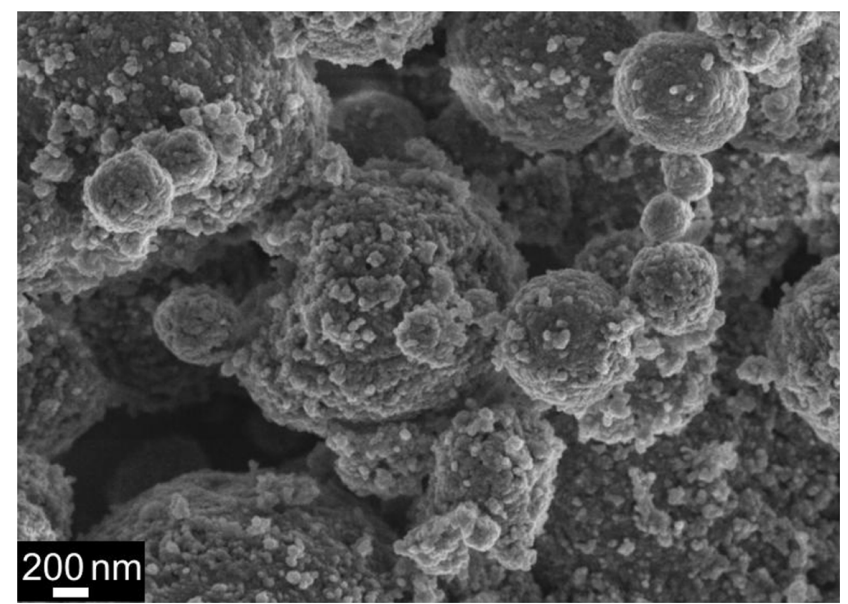

Figure I SEM micrograph of NanoXIM20I nanopowder (Fluidinova, Moreira da Maia, Portugal).

Abbreviation: SEM, scanning electron microscopy.

spherical agglomerates. NanoXIM201 is available for medical device applications in the form of nanopowder, which is in compliance with the ISO13779 and ASTM F1185 standards requests for medical application.

Additionally, during the $\mathrm{X}$-ray diffraction (XRD) analysis a plate from a pig's shank bone was used as a reference of natural apatite.

\section{Powder XRD}

The phase composition of the reaction products was analyzed by powder XRD (X'Pert PRO diffractometer, $\mathrm{Cu}$ Kal radiation; PANalytical BV, Almelo, The Netherlands). The patterns were collected at room temperature in the 2 theta range $10^{\circ}-150^{\circ}$ and with a step of $0.03^{\circ}$. Pattern analysis was performed by whole pattern fitting (the Rietveld method) using the DBWS-9807a code. ${ }^{22}$

\section{Density and SSA measurements}

The density measurements were performed using a helium pycnometer (AccuPyc, model 1330; Micromeritics, Gosford, Australia) using an in-house procedure. ${ }^{23}$ The specific surface area of the powders was measured by the BET method (AccuPyc, model Gemini 2360; Micromeritics). The average diameter of the particles was calculated based on the SSA and density, assuming that all of the particles were spherical and identical..$^{23}$

\section{Morphology analysis}

The morphology of the nanopowder samples was examined with SEM (LEO 1530; Carl Zeiss Meditec AG, Jena, Germany) and transmission electron microscopy (TEM) (JEM2000EX; JEOL, Tokyo, Japan). The TEM 
investigations, high-resolution TEM, and selected area electron diffraction were conducted at $200 \mathrm{kV}$. The specimens for the TEM observations were prepared by dropping the methanol particle dispersion, created by an ultrasonic technique, on a carbon film supported on a 300-mesh copper grid. Additionally, TEM studies were used to determine the nanoparticle size distribution. The grain size histograms were obtained by considering a region of a sample having about 250 nanocrystals and approximating the shape of each nanocrystal by a sphere. The obtained histograms were fitted to either normal or log-normal distributions (Chi-squared test and Pearson's coefficient).

\section{Chemical composition analysis}

The chemical composition of the powders was determined by inductively coupled plasma optical emission spectrometry (ICP-OES), with induction in argon plasma (Jobin-Yvon model 138 Ultrace; HORIBA Scientific, Kyoto, Japan).

\section{Degradation test}

The determination of material solubility was performed according to norm ISO 10993-14: biological evaluation of medical devices - identification and quantification of degradation products from ceramics. The material was tested in the form of a $6 \mathrm{~mm}$ disk (each disk was around $35 \mathrm{mg}$ and was created from the nanopowder using a laboratory hydraulic press under $5 \mathrm{MPa}$ pressure) and was placed in $200 \mathrm{~mL}$ of buffer solution (tris(hydroxymethyl)aminomethane hydrochloride [TRIS-HCl] buffer with $\mathrm{pH} 7.4 \pm 0.1$ ). A simulation solution test, lasting 28 days, was conducted without buffer solution exchange during the entire test. All calcium ion concentration measurements were conducted with an ion-selective electrode (Schott ProLab 2000 GLP equipped with calcium ion electrode type CA60; SI Analytics GmbH, Mainz, Germany).

\section{Thermal analysis}

The thermal analysis of the HAp samples (approximately $5 \mathrm{mg}$ ) was conducted by thermogravimetry and differential scanning calorimetry measurements (TG-DSC) - (STA 449 F1 Jupiter; NETZSCH-Feinmahltechnik GmbH, Selb, Germany). The samples were heated at a rate of $5^{\circ} \mathrm{C} /$ minute to $1350^{\circ} \mathrm{C}$ under a helium gas flow. In the same time the released gases were analyzed by quadrupole mass spectrometry (403 Aëolos; NETZSCH-Feinmahltechnik GmbH).

Additionally, the samples before and after heating were examined by a Fourier transform infrared spectroscopy (FTIR) spectrometer (Bruker Optics Tensor 27; Bruker Corporation, Billerica, MA, USA) equipped with a diamond attenuated total reflectance (ATR) accessory. The diamond ATR-crystal was soldered onto a ceramic plate, resulting in a chemically inert and mechanically rugged sampling area. All ATR-FTIR spectra were recorded at room temperature in the $4000-400 \mathrm{~cm}^{-1}$ range. The spectral resolution and accuracy were $4 \mathrm{~cm}^{-1}$ and $\pm 1 \mathrm{~cm}^{-1}$, respectively.

\section{Biocompatibility study in vitro \\ Isolation and culture of cells used for biocompatibility study in vitro}

Human bone-derived cells (HBDC) were isolated from bone fragments which were amputated from the distal end of the femur during orthopedic surgery and which would have otherwise been discarded. The cells investigated in separate experiments were derived from two different donors. The team obtained the appropriate consent of the Bioethics Committee of the Polish Department of Health to use such biological material for experimental purposes (decision number $\mathrm{KB} / 74 / 2005$ ) and the donors provided informed consent.

The HDBC isolation procedure was based on the protocols described by Gallagher et al with modifications. ${ }^{24,25}$ After confluence was reached, cells were detached from the culture flasks using collagenase XI S (200 U/mL) (Sigma-Aldrich, St Louis, MO, USA) and $0.25 \%$ trypsin suspension, and were used for experiments. Cells were grown in a Dulbecco's modified Eagle's medium ([DMEM] Gibco; Life Technologies, Carlsbad, CA, USA)-based medium supplemented with 10\% fetal bovine serum (Gibco), 1\% L-glutamine (Gibco), $1 \%$ antibiotic-antimycotic mixture (Gibco), and L-ascorbic acid 2-phosphate (Sigma-Aldrich) at a concentration of $34 \mu \mathrm{g} / \mathrm{mL}$.

\section{Cell culture on the surface of the tested materials}

GoHAP and the reference NanoXIM samples were prepared in the form of disks (6 mm diameter, fit to the 96-well culture dishes) using the same disk preparation procedure as described in the degradation test.

Prior to use, the samples were sterilized by irradiation (25 kGy dose) and pre-wetted for 24 hours in a culture medium of the same composition as used in the cell culture. The appropriate samples were placed at the bottom of the 96-well or 24-well tissue culture dishes. The first system was used for quantitative assays while the second one was used for morphological observations. Cells were seeded onto the surface of the examined materials at a density of $2.5 \times 10^{4}$ cells $/ \mathrm{cm}^{2}$. Cells that were cultured on the bottom of tissue-culture polystyrene dishes (TCP) served as a positive control. For the first 24 hours, cells were cultured in a medium 
identical with the one used at the isolation stage. Next, the medium was replaced by a commonly used osteogenic medium, ie, it was additionally supplemented with $10 \mathrm{nM}$ dexamethasone (Sigma-Aldrich) and glycerol-2 phosphate (Sigma-Aldrich) at a concentration of $10 \mathrm{mM}$. All measurements and morphology assays were performed on Day 1 (ie, after the first 24 hours of culture in an osteogenic medium) and then subsequently on Days 7 and 14.

\section{Morphological observations of cells in direct contact with the material} Cell morphology observations in light microscope

The HBDC's morphology was examined both on the surface of the investigated materials (in order to observe cell spreading in direct contact with the surface of the materials), and on the plastic next to the samples. The latter allowed for noninvasive monitoring of the cells' wellness during the entire experiment, as well as observation of the cells that floated from the surface of the material and stayed in the same culture adjacent to the investigated material. The observations were performed by phase contrast microscopy (Eclipse TE2000-U; Nikon Corporation, Tokyo, Japan) connected to a Nikon Digital Sight DS-U1 camera. At least two samples of each type were examined at each time point.

\section{Live/dead viability assay}

The viability of the cells cultured on the surface of the investigated samples was qualitatively assessed using live/dead fluorescent staining, based on fluorescein diacetate (FDA) and propidium iodide (PI). Both staining kits were purchased from Invitrogen (Carlsbad, CA, USA), and the staining was performed according to the manufacturer's instructions. The viable cell cytoplasm was labeled green, while the nonviable cell nuclei were labeled red. The principle of the test is that hydrophobic FDA enters a living cell by passing through the hydrophobic cell membrane, and it is then converted to hydrophilic fluorescein by esterase. Fluorescein slowly accumulates in the cell since there is low permeability of the membrane to fluorescein. Accumulation is not possible in dead cells because of the membrane perforation. ${ }^{26}$ PI intercalates into double-stranded nucleic acids. It is membraneimpermeant and generally excluded by viable cells, but it can penetrate the cell membranes of dying or dead cells. After staining, the cells were covered with the culture medium. Live cells were observed under the microscope in blue light (wavelength of excitation/emission: $494 \mathrm{~nm} / 518 \mathrm{~nm}$ ) and dead cells were observed in green light (wavelength of excitation/emission: $536 \mathrm{~nm} / 617 \mathrm{~nm}$ ).

\section{SEM}

After viability staining, the osteoblasts grown on the samples were fixed in the $2.5 \%$ glutaraldehyde solution in a $0.2 \mathrm{M}$ cacodyl buffer, washed, dehydrated through a graded ethanol series, and air-dried. An SEM examination was performed using SEM microscopy as in the nanopowder morphology studies.

A morphological analysis was performed in two independent experiments using cells from two different donors.

\section{Quantitative assays of the cells cultured on the surface of tested biomaterials}

\section{Viability assay}

The 2,3-bis-(2-methoxy-4-nitro-5-sulfophenyl)-2H-tetrazolium-5-carboxanilide (XTT) assay was applied. This assay is based on the capacity of mitochondrial dehydrogenase enzymes in living cells to convert the XTT substrate (SigmaAldrich), yellow tetrazolium salt (2.3-bis-(2 methoxy-4-nitro5-sulfophenyl)-5-[(phenyloamino)carboxyl]-2H-tetrazolium hydroxide) into a water soluble product, which is orange formazan dye. ${ }^{27}$ The absorbance of the supernatant (the final product of the reaction) was read at $450 \mathrm{~nm}$ in the enzymelinked immunosorbent assay reader (FLUOstar OPTIMA; BMG LABTECH GmbH, Ortenberg, Germany). The results of the XTT assay are believed to be proportional to the number of living cells. ${ }^{28}$ The test was performed for cells cultured on the GoHAP and NanoXIM samples, as well as in the TCP control. In most cases, six wells of each type were examined at every time point. The measurements were performed in two independent experiments.

\section{DNA assay}

After the XTT assay, the cells were washed twice with phosphate-buffered saline and then treated with $120 \mu \mathrm{L}$ of lysis buffer (0.1\% Triton X-100; Sigma-Aldrich) in $10 \mathrm{mM}$ Tris-HCl (Sigma-Aldrich), pH 7.4, for 12 hours (overnight) with constant stirring at $4^{\circ} \mathrm{C}$. After incubation the plates with cell lysate were stored at $-20^{\circ} \mathrm{C}$ to increase the effectiveness of cell lysis. The Picogreen assay was used, which is based on the PicoGreen reagent (Invitrogen). The assay uses an asymmetrical cyanine dye, which as a free dye does not fluoresce, but when bound to double-stranded DNA it exhibits a 1000-fold fluorescence enhancement. On the day the measurements were planned, the cell lysate was thawed at $4{ }^{\circ} \mathrm{C}$. The PicoGreen assay was performed according to the manufacturer's instructions. The fluorescence was read at a wavelength of excitation/emission of $485 \mathrm{~nm} / 538 \mathrm{~nm}$. The data were related to the DNA standard curve. The test 
was performed for cells cultured on both the GoHAP and the NanoXIM samples as well as on the TCP control. In most of the cases, six wells of each type were examined at every time point. The measurements were performed in two independent experiments.

\section{Biocompatibility examination of the extracts from the tested biomaterials}

The assays were carried out in accordance with ISO Standard 10993-5:2009. ${ }^{29}$

The culture medium was chosen as an extraction vehicle. Sterile powders of GoHAP and NanoXIM (irradiation, $25 \mathrm{kGy}$ ) were suspended at a concentration of $50 \mathrm{mg} / \mathrm{mL}$. Extract of corundum $\left(\mathrm{Al}_{2} \mathrm{O}_{3}\right)$, which is well known as an inert biomaterial, served as a negative control. ${ }^{30,31}$ Extraction was performed for 24 hours with constant stirring at $37^{\circ} \mathrm{C}$. After this time, the extracts were centrifuged (MPW-35OR, 10 minutes, $5000 \mathrm{rpm} / \mathrm{minute})$. Supernatants were collected and centrifuged two more times to obtain the clear extracts used in the experiments. The Triton X-100 (Sigma-Aldrich) $0.1 \%$ solution in a culture medium served as a positive control.

The HBDCs were seeded at a density of $1.1 \times 10^{4}$ cells per well in 96-well plates, and cultured in DMEM supplemented with $10 \%$ fetal bovine serum, $1 \%$ antibiotic-antimycotic mixture, $1 \%$ L-glutamine, and $34 \mu \mathrm{g} / \mathrm{mL}$ L-ascorbic acid 2 -phosphate. When they reached confluence covering 70\% of the well surface, the medium was changed for prepared extracts in a volume of $200 \mu \mathrm{L}$ per well. Cells were exposed to the following extracts concentrations: $100 \%, 50 \%, 25 \%$, and $12.5 \%$. After 24 hours cell morphology was examined under a phase contrast microscope, an XTT assay was performed. Then, cells were lysed and DNA was measured by means of a PicoGreen assay. At least five wells were tested in all groups and the entire procedure was repeated in two separate experiments.

\section{Statistical analysis}

All values were presented as mean \pm standard deviation. The differences between experimental groups were statistically assessed using the Kruskal-Wallis Test (nonparametric ANOVA) with Dunn's multiple comparisons test. $P<0.05$ was considered to indicate statistically significant differences.

\section{Results and discussion}

\section{Nanoparticles characterization}

A typical density for HPa micropowder is $3.05 \mathrm{~g} / \mathrm{cm}^{3} .{ }^{32}$ In the case of GoHAP the density was lower by almost $4 \%$ and it was $2.93 \mathrm{~g} / \mathrm{cm}^{3}$. The specific surface area was $236 \pm 5 \mathrm{~m}^{2} / \mathrm{g}$, and, assuming that the particles were spherical, the average particle diameter calculated on the basis of SSA measurements was $9 \mathrm{~nm}$. The lower density of nanoparticles than in conventional material is in agreement with the literature, which indicated that in the case of nanoparticles, there is a reduction in the material density caused by high contribution of surface layers, which are less densely packed than the bulk. ${ }^{33}$

The XRD analysis was conducted on GoHAP, commercial HAp (NanoXIM), and a plate from a pig's shank bone (Figure 2). The XRD results confirmed that the material is a pure well crystalline hexagonal HAp with nano-sized particles. No indication of the presence of other crystalline phases or any amorphous component was found. The lattice parameters were: GoHAP a $=9.43(4), \mathrm{c}=6.86(5)$; NanoXIM a =9.42(3), $\mathrm{c}=6.90(5)$; and bone $\mathrm{a}=9.42(5)$, $\mathrm{c}=6.87(7)$. Other structure parameters, except NanoXIM powder, could not be derived with adequate precision, due to the considerable size anisotropy and a very small crystal size. NanoXIM's average particle size calculated by the Scherrer equation was $17 \mathrm{~nm}$. Comparison of the diffraction patterns of the analyzed samples suggested that the crystallites in GoHAP were very similar in size to those in the bone, while those in NanoXIM were considerably larger.

An ICP-OES analysis indicated that the $\mathrm{Ca} / \mathrm{P}$ molar ratio was 1.57 , which was close to the natural bone molar ratio of the calcium and phosphor elements. Additionally, GoHAP also contains magnesium (0.22 wt\%), silicon $(0.025 \mathrm{wt} \%)$, sodium $(0.0125 \mathrm{wt} \%)$, and manganese (0.0075 wt \%).

The morphology investigation was conducted with SEM and TEM techniques. Figure 3 shows SEM micrographs of the obtained HAp nanoparticles. Strong homogeneity of the obtained nanopowder was observed. The average particle sizes of the synthesized HAp were in the range of 5-20 nm.

A TEM examination showed that the GoHAP has space group P.P63/m of a hexagonal crystal structure with the following parameters: $\mathrm{a}=9.424(4) \AA$ and $\mathrm{c}=6.879(4) \AA .{ }^{34}$ The analysis did not identify any additional structures in the tested sample. Figure 4 shows the selected area electron diffraction with identified planes. All particles had a needlelike shape (Figure 5), with an aspect ratio (calculated as the ratio of length to width) in the range of 2 to 5 . The average grain size for the individual samples was $5.6 \pm 1.1 \mathrm{~nm}$ (Figure 5). 


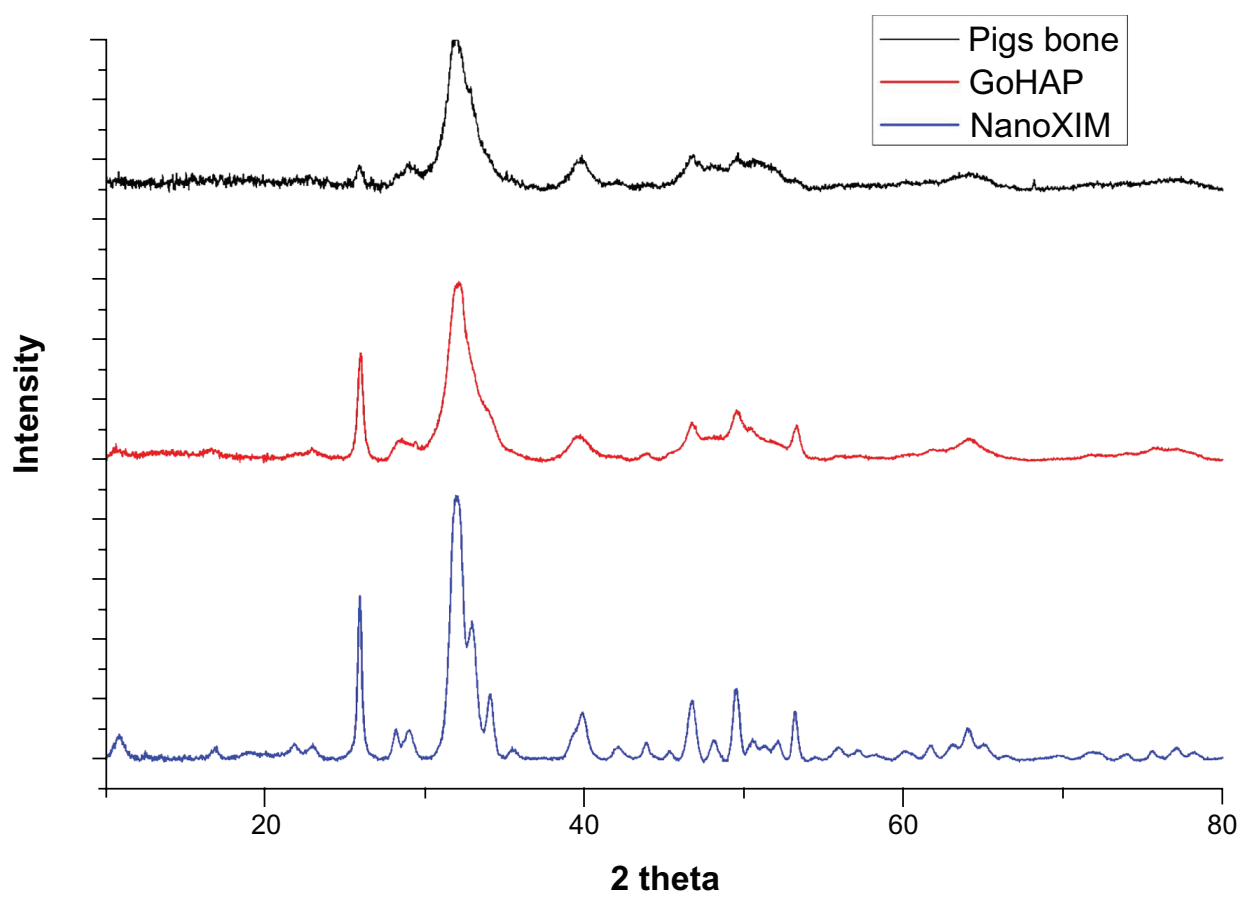

Figure 2 XRD patterns of HAp particles: in pigs bone, GoHAP, and NanoXIM (Fluidinova, Moreira da Maia, Portugal).

Abbreviations: XRD, X-ray diffraction; HAp, hydroxyapatite.

\section{Thermogravimetric analysis}

\section{DSC-TG-MS analysis}

Figure 6 shows the results of the GoHAP thermal behavior during heating up to $1350^{\circ} \mathrm{C}$. The DSC curve shows two endothermic transformations with the onset temperature $375^{\circ} \mathrm{C}$ (herein called the thermal transformation) and $790^{\circ} \mathrm{C}$ (herein called the second thermal transformation) (Figure 6A). The loss of weight (Figure 6) from room temperature to the first thermal transformation was $7.4 \mathrm{wt} \%$

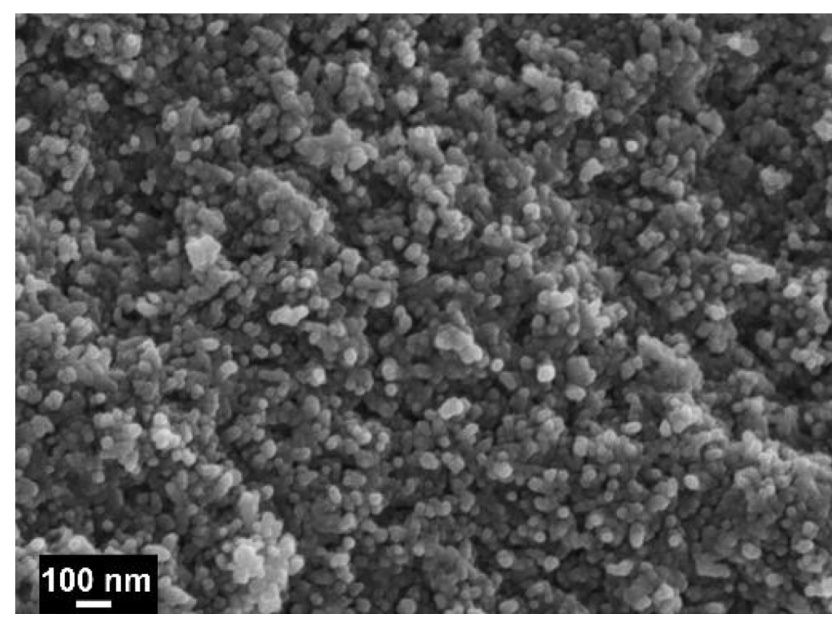

Figure 3 SEM micrograph of GoHAP nanoparticles shows homogeneity of HAP nanopowder.

Note: 100 k zoom (energy $2.00 \mathrm{kV}$ )

Abbreviations: SEM, scanning electron microscopy; HAp, hydroxyapatite. and it was caused by the release of water. The first transformation $(\Delta \mathrm{H}=-671.2 \mathrm{~J} / \mathrm{g})$ caused $1.9 \mathrm{wt} \%$ loss due to the dehydroxylation of material. ${ }^{13}$ At $790^{\circ} \mathrm{C}(\Delta \mathrm{H}=-870.9 \mathrm{~J} / \mathrm{g})$, the second endothermic transformation of HAp took place. After the second thermal transformation, further heating to the $1350^{\circ} \mathrm{C}$ caused $3.4 \%$ weight loss, which was linked to further dehydroxylation. The total amount of released gases from room temperature to the $1350^{\circ} \mathrm{C}$ was about $15 \mathrm{wt} \%$.

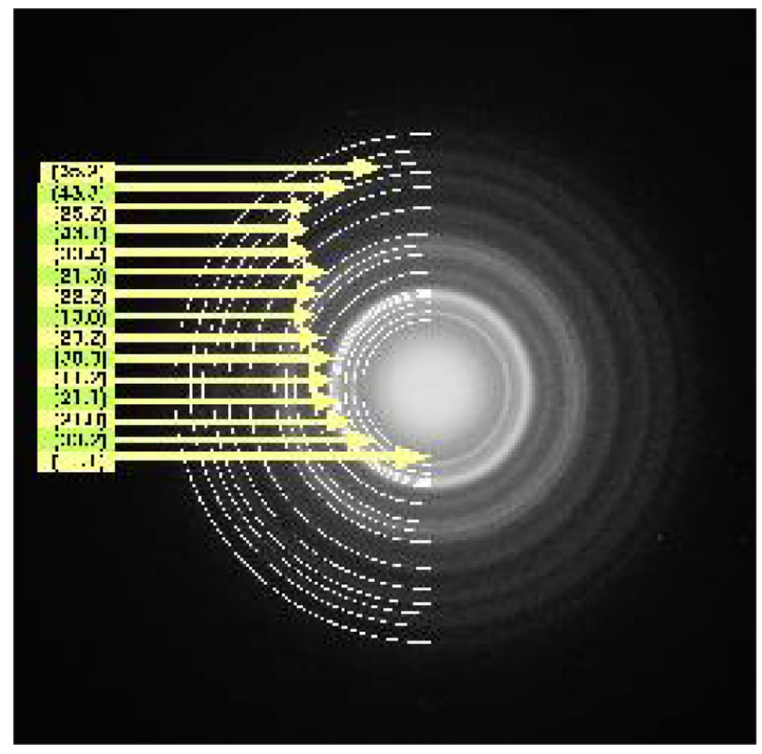

Figure 4 SAED with the identified planes. Abbreviation: SAED, selected area electron diffraction. 
A

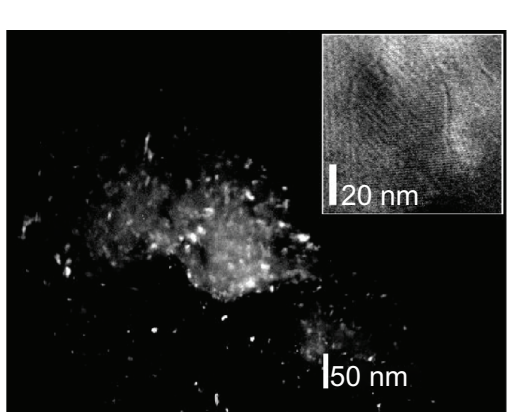

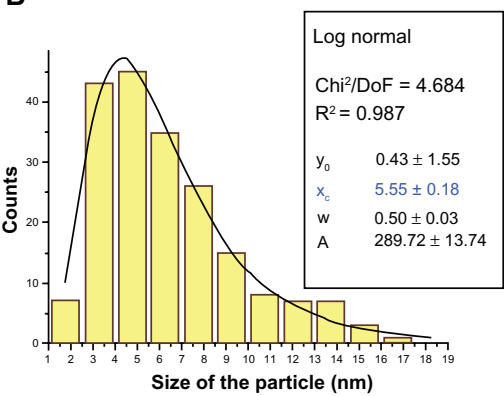

Figure 5 TEM investigation of GoHAP powder. (A) Dark field TEM image of GoHAP particles. (B) Histogram of the particle size distribution. Abbreviation: TEM, transmission electron microscopy.
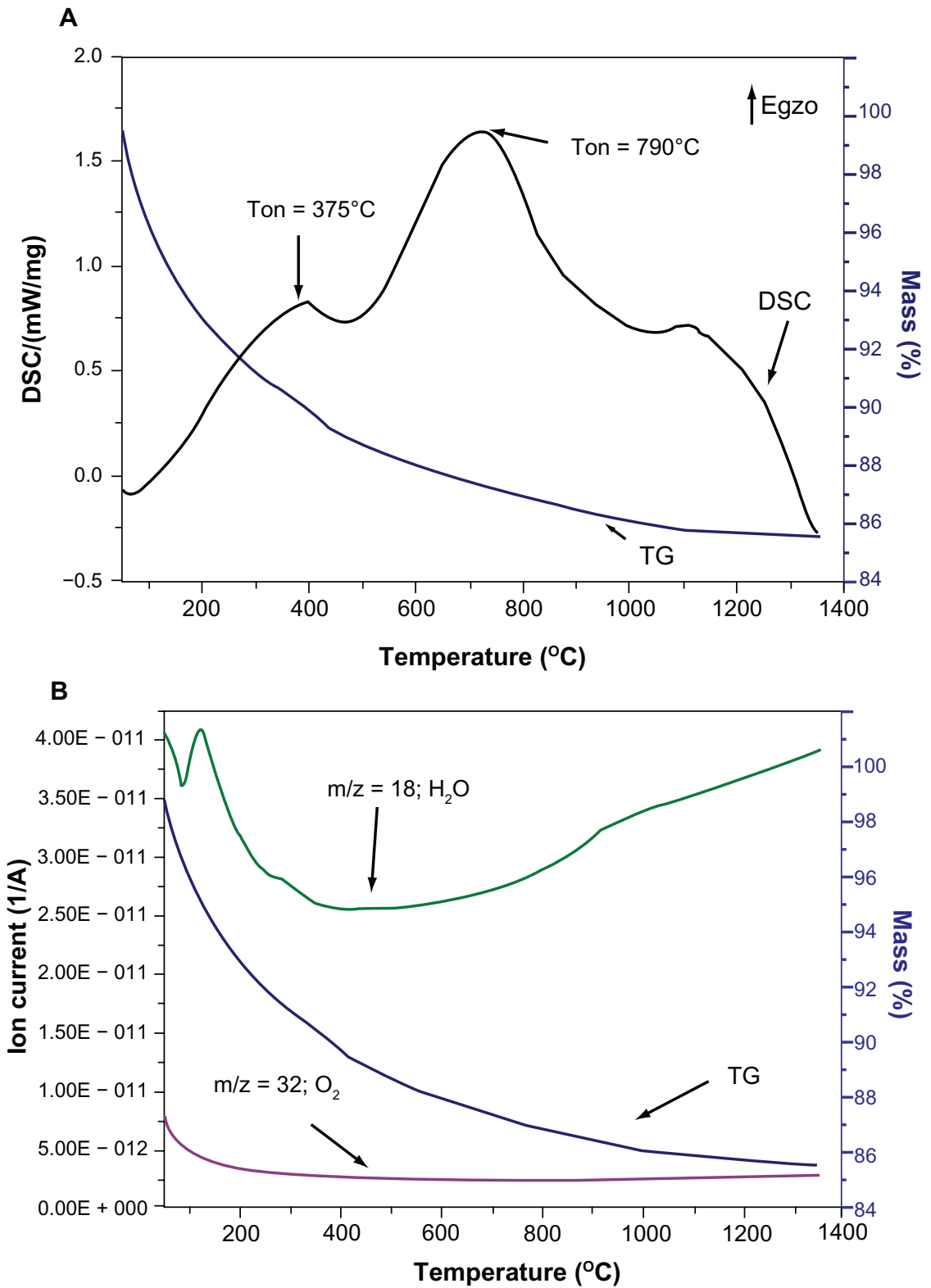

Figure $6 \mathrm{TG}$ analysis of GoHAP powder. (A) DSC-TG results of GoHAP heated with a linear ramp $5^{\circ} \mathrm{C} /$ minute to $1350^{\circ} \mathrm{C}$ in a helium atmosphere. (B) TG-MS results of GoHAP. Note: The mass signal of $\mathrm{H}_{2} \mathrm{O}$ and $\mathrm{O}_{2}$ are shown.

Abbreviations: DSC, differential scanning calorimetry; TG, thermogravimetry; MS, mass spectra. 


\section{FTIR analysis}

The GoHAP samples as-synthesized and samples after heating at a rate of $5^{\circ} \mathrm{C} /$ minute to different temperatures by the ATR technique of FTIR were investigated. Figure 7A shows the FTIR spectra in the $4000-450 \mathrm{~cm}^{-1}$ range, with the spectral whole (about $2300-2100 \mathrm{~cm}^{-1}$ ) characteristic of diamond crystal. Additionally, Figure 7B shows the magnification of the spectra for clarity.

The as-synthesized HAp spectra showed typical bands coming from $\mathrm{PO}_{4}^{3-}$. These bands were broadband with a maximum about $1022 \mathrm{~cm}^{-1}$, and another band with two maxima at 601 and $561 \mathrm{~cm}^{-1}$ in the low wavenumbers (Figure 7B). Additionally, bands coming from adsorbed water at 3294 and $1666 \mathrm{~cm}^{-1}$ and from $\mathrm{CO}_{2}$ coming from air at $2977-2848 \mathrm{~cm}^{-1}$ can be also seen (Figure 7A). ${ }^{35,36}$ Furthermore, a peak at $804 \mathrm{~cm}^{-1}$ origin from the $\mathrm{OH}^{-}$deformation band in HAp (Figure 7B) was observed.
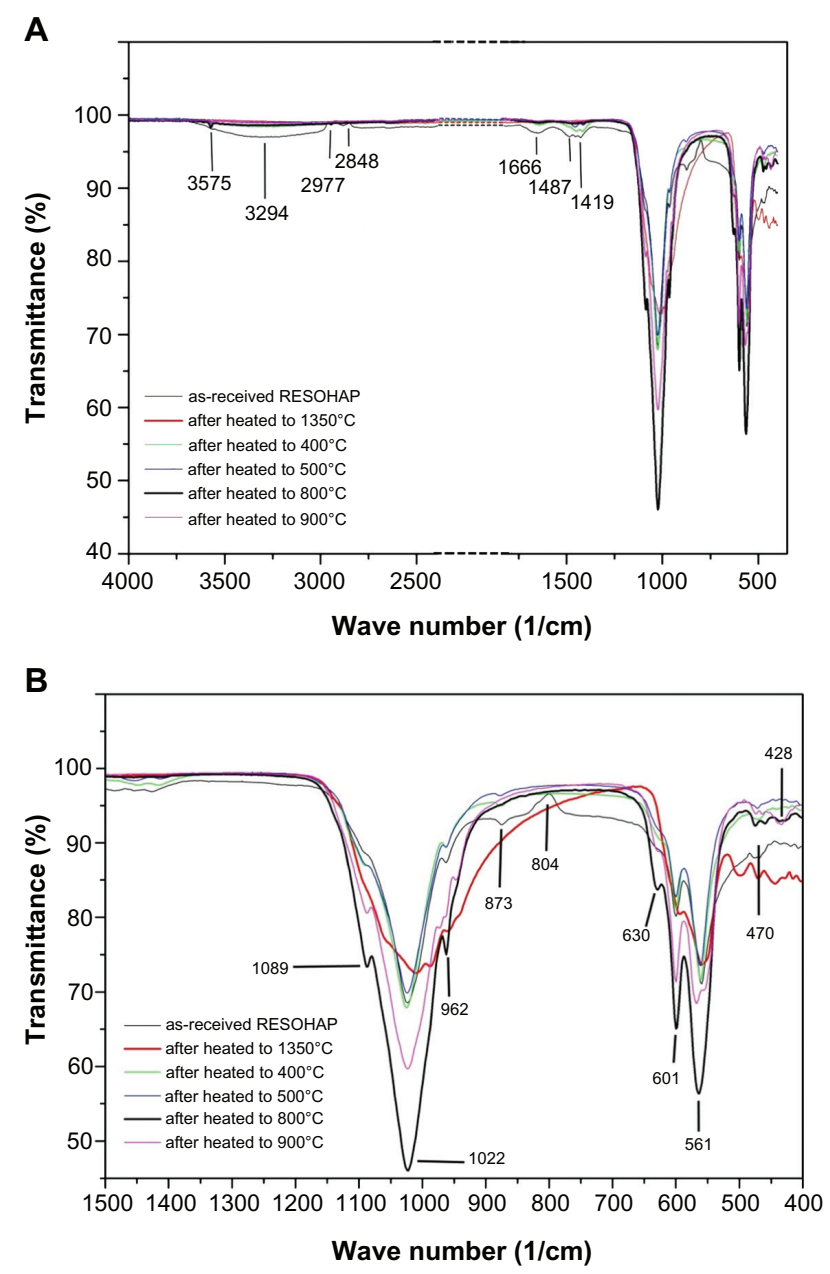

Figure 7 FTIR spectra of the investigated hydroxyapatite samples. Magnification in the wavenumber range 4000 to $400 \mathrm{~cm}^{-1}$ (A) and 1500 to $400 \mathrm{~cm}^{-1}$ (B).

Abbreviation: FTIR, Fourier transform infrared spectroscopy.
After heating the sample above the first thermal transformation temperature $\left(400^{\circ} \mathrm{C}\right.$ and $\left.500^{\circ} \mathrm{C}\right)$, bands were observed coming from adsorbed water (3294 and $1666 \mathrm{~cm}^{-1}$ ), carbonate $\left(1487-1419,873 \mathrm{~cm}^{-1}\right)$, and noticeable $\mathrm{PO}_{4}^{3-}$ vibrations that consisted of asymmetric stretching bands P-O v $v_{3}(1022$ and $1089 \mathrm{~cm}^{-1}$ ), antisymmetric bending bands O-P-O $v_{4}$ $\left(561 \mathrm{~cm}^{-1}\right)$ and stretching bands P-O $v_{1} 962 \mathrm{~cm}^{-1}$, symmetric bending bands O-P-O v $601 \mathrm{~cm}^{-1}$, and bending bands O-P-O $v_{2}$ at $470 \mathrm{~cm}^{-1}$ (Figure 7B). ${ }^{13,35}$

The spectra of the sample heated above the second thermal transformation $\left(800^{\circ} \mathrm{C}\right)$ were characterized by additional bands coming from $\mathrm{OH}^{-}$vibrations, which are typical for stoichiometric HAp. ${ }^{37,38}$ These were the symmetric stretching bands at $3575 \mathrm{~cm}^{-1}$ (Figure 7A) and bending bands at $630 \mathrm{~cm}^{-1}$, which are also characteristic of the sample heated to $900^{\circ} \mathrm{C}$. The material after heating to $1350^{\circ} \mathrm{C}$ presented a fade of the $\mathrm{OH}^{-}$and $\mathrm{CO}_{3}{ }^{2-}$ signals. Only two typical bands of $\mathrm{PO}_{4}^{3-}$ were observed; one broadband at $1022 \mathrm{~cm}^{-1}$, and a second with two clear maxima at the lower wavenumbers 601 and $561 \mathrm{~cm}$.

A thermal stability investigation clearly showed that the obtained material is stable in the temperature range room temperature to $1350^{\circ} \mathrm{C}$ with two endothermic transformations, the first at a temperature of $375^{\circ} \mathrm{C}$ and the second at $790^{\circ} \mathrm{C}$. Before and during the first transformation, the material loses weight due to water desorption and material dehydroxylation. The TEM investigation did not indicate any changes in the material structure caused by the first transformation. In comparison to the starting material, it was seen that the average grain size increased to $14.4 \mathrm{~nm}$, and that the powder changed its morphology from needle-like grains to a mixture of different shapes, ranging from spherical to needle-like (Figure 8). An ICP-OES analysis of the sample after the first transformation indicated a $\mathrm{Ca} / \mathrm{P}$ molar ratio after heating of 1.59 , which was slightly larger than the ratio in the starting material (1.57). Furthermore, in comparison to the stoichiometric HAp powders with a $\mathrm{Ca} / \mathrm{P}$ molar ratio equal to 1.67 , it showed deep nonstoichiometry. The second transformation was also connected with the further dehydroxylation of the material. A FTIR analysis at temperatures over $800^{\circ} \mathrm{C}$ indicated the presence of additional bands coming from $\mathrm{OH}^{-}$vibrations, which are typical for stoichiometric HAp.

\section{Degradation test}

The tested samples (GoHAP, NanoXIM, GoHAP after the first thermal transformation - herein called GoHAP 375, and a blind sample that was included to measure background changes) were incubated according to norm ISO 10993-14 in 

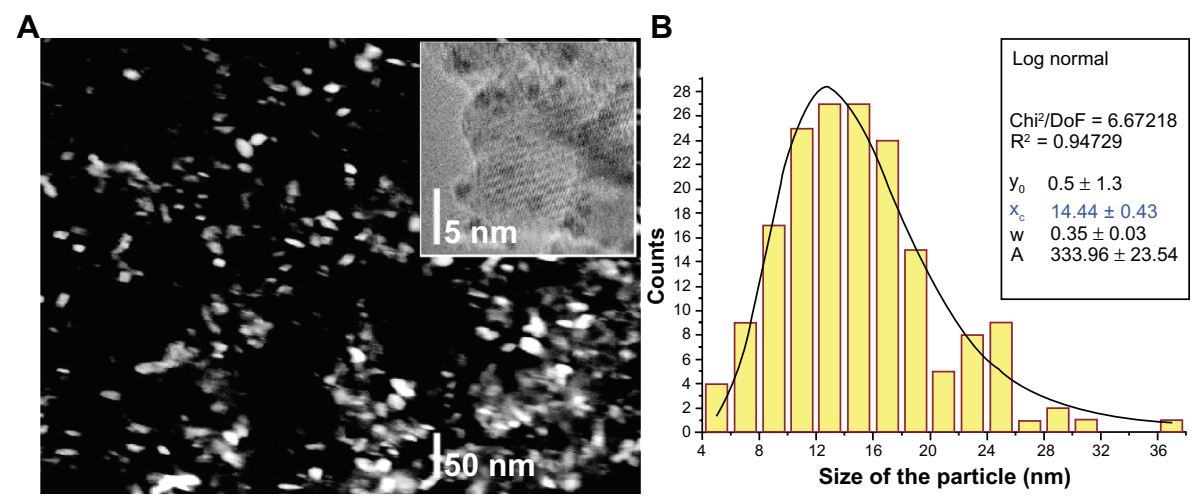

Figure 8 TEM investigation of GoHAP powder after the first thermal transformation. (A) Dark field TEM image of GoHAP after thermal transformation. (B) Histogram of the particle size distribution.

Abbreviation: TEM, transmission electron microscopy.

a TRIS- $\mathrm{HCl}$ solution at $37.0^{\circ} \mathrm{C}$ for 28 days. The initial $\mathrm{pH}$ of the test solution was 7.49 , the conductivity was $6.68 \mathrm{mS} / \mathrm{cm}$, and the calcium ion concentration was $0.466 \mu \mathrm{mol} / \mathrm{dm}^{3}$. Along with the degradation of the samples, the $\mathrm{pH}$, conductivity, and calcium ion concentration values were measured three times per week. The results of the calcium ion concentration changes are shown in Figure 9.

The results showed that in each day GoHAP increased its solubility slightly faster than NanoXIM and GoHAP 375. After this period the calcium ion concentration in the sample with NanoXIM remained almost constant; after 28 days of testing its value was $40.37 \mu \mathrm{m} / \mathrm{dm}^{3}$, which could be recalculated based on weight solubility to $4.0 \mathrm{mg} / \mathrm{dm}^{3}$. After 3 weeks of testing GoHAP had twice as much solubility as NanoXIM, and furthermore, in week 4 there was an acceleration of material solubility, which after 28 days of testing led to the achievement of $199.6 \mu \mathrm{mol} / \mathrm{dm}^{3}$ calcium ion concentration, equal to $20.0 \mathrm{mg} / \mathrm{dm}^{3}$. The GoHAP 375 sample achieved solubility $4.3 \mathrm{mg} / \mathrm{dm}^{3}$ after 28 days which is close to NanoXIM results. The conductivity of the solution for GoHAP increased rapidly in the first 3 weeks of the test, to a value of $7.11 \mathrm{mS} / \mathrm{cm}$, and decreased in week 4 to $7.00 \mathrm{mS} / \mathrm{cm}$. The solution with the NanoXIM sample increased its conductivity at the same pace throughout the test to achieve a final value of $7.01 \mathrm{mS} / \mathrm{cm}$, without any rapid changes during the 28 days of experimentation. For the $\mathrm{pH}$ measurements there were no crucial differences between the tested materials. The starting $\mathrm{pH}$ was 7.49 and its final value ranged from 7.55 for NanoXIM to 7.56 for GoHAP.

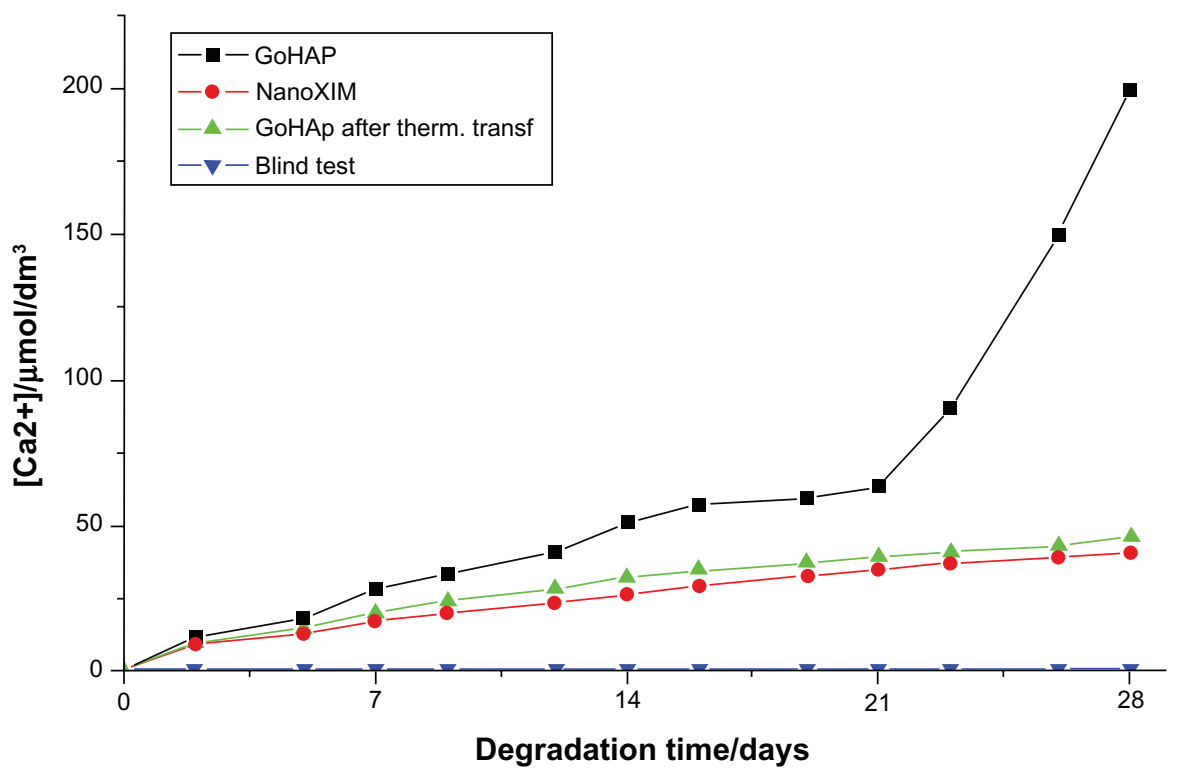

Figure 9 Calcium ion concentration changes for GoHAP, NanoXIM nanopowder (Fluidinova, Moreira da Maia, Portugal), and GoHAP after the first thermal transformation, and a blind test.

Abbreviation: HAp, hydroxyapatite. 
The degradation test was additionally followed by a determination of the weight loss after 28 days of testing. During the test, NanoXIM lost $4 \%$ of its original weight, resulting in $7.0 \mathrm{mg} / \mathrm{dm}^{3}$ of solubility, and GoHAP lost over $22 \%$ of its initial weight, equal to $38.5 \mathrm{mg} / \mathrm{dm}^{3}$. In both the calcium ion concentration and the weight loss measurements, GoHAP had five times greater solubility than NanoXIM. The solubility measured by weight loss was in all cases almost twice as large as the solubility measured by changes in the calcium ion concentration, probably due to nanopowder dispersing. As the SEM investigations showed, the samples of GoHAP after testing were deeply cracked (Figure 10A) but kept their original disk shape. The NanoXIM disks were so weak after the test, that it was impossible to transfer them in one piece to a microscope (Figure 10B shows a fragment of original disk), but their surfaces were not as regularly cracked as the GoHAP disks. GoHAP 375 had a solubility value comparable to NanoXIM $\left(8.1 \mathrm{mg} / \mathrm{dm}^{3}\right)$, and its disk kept its shape and had a low cracking level after the test period.

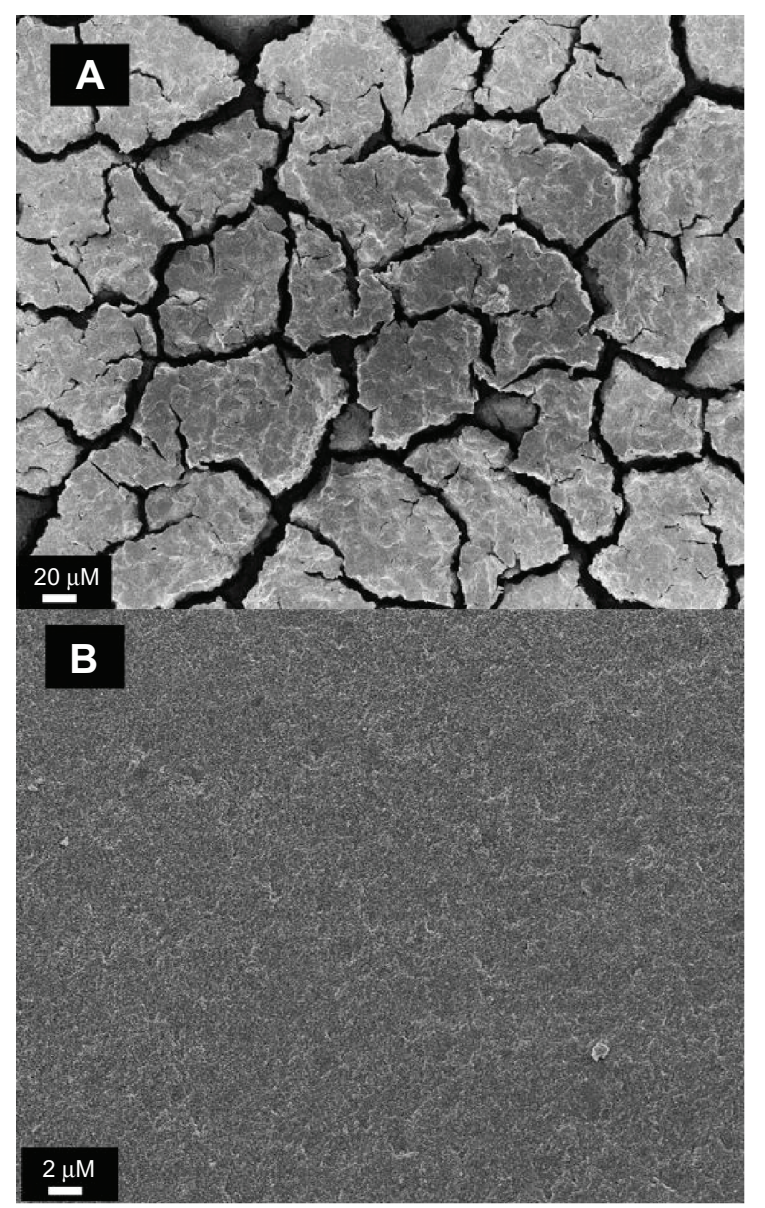

Figure 10 SEM micrographs of the GoHAP disk (A) and the commercial NanoXIM (Fluidinova, Moreira da Maia, Portugal) disk (B).

Abbreviation: SEM, scanning electron microscopy.
A biodegradation test clearly showed that GoHAP before the thermal transformation had a rate of degradation five times as large as NanoXIM. This test proved the unique properties and strong potential for future applications of this nanopowder. Additionally, the biodegradation study showed that during the first thermal transformation, GoHAP lost its unique properties and became similar in its rate of biodegradation to commercially available HAp nanopowder.

\section{Biocompatibility study in vitro Osteoblasts morphology}

At 24 hours after seeding, the morphology of the cells on the culture plastic of the wells with both nanohydroxyapatite samples were comparable with the control, which was culture plastic without sample (TCP). Both correctly showed flattened cells with a phenotype typical for osteoblasts (data not shown). After confirming the adherence of the cells to the plastic, the medium was changed.

At 24 hours after changing to an osteoblastic medium, there was no difference between the morphology of the cells on the surface of the culture plastic next to the tested samples and the morphology of the control cells on the culture plastic without tested samples (Figure 11A and B). It was possible to observe a difference after fluorescent staining of the cells on the samples, with FDA staining the living cells (green color) and PI staining the dead cells (red color) (Figure 11C and D). No vacuolization or cell membrane lysis was found on the surface of any of the tested materials and only single dead cells were detected. Live cells were observed on both samples but they differed in their level of adhesion to the surface of the sample. On NanoXIM (Figure 11C) most of the cells were oval and poorly flattened, while on GoHAP (Figure 11D) the cells were similar in their morphology to those on culture plastic; they were flattened and seemed to adhere firmly to the surface of the sample.

On day 7, a significantly higher cell concentration was visible on the surface of the culture plastic around GoHAP compared with the wells with NanoXIM, although the cell morphology was similar to the control in both cases (Figure 11E and F). However, the cells visualized on the surface of the biomaterials at the same point in time had a substantially different morphology. GoHAP was covered by cells over its entire surface that were evenly adhered to the material and built a confluent layer (Figure 11H). The cells had a spindle lengthened shape, and only a few dead cells were found. In contrast, not all of the cells on the surface of NanoXIM showed the correct morphology (Figure 11G). 


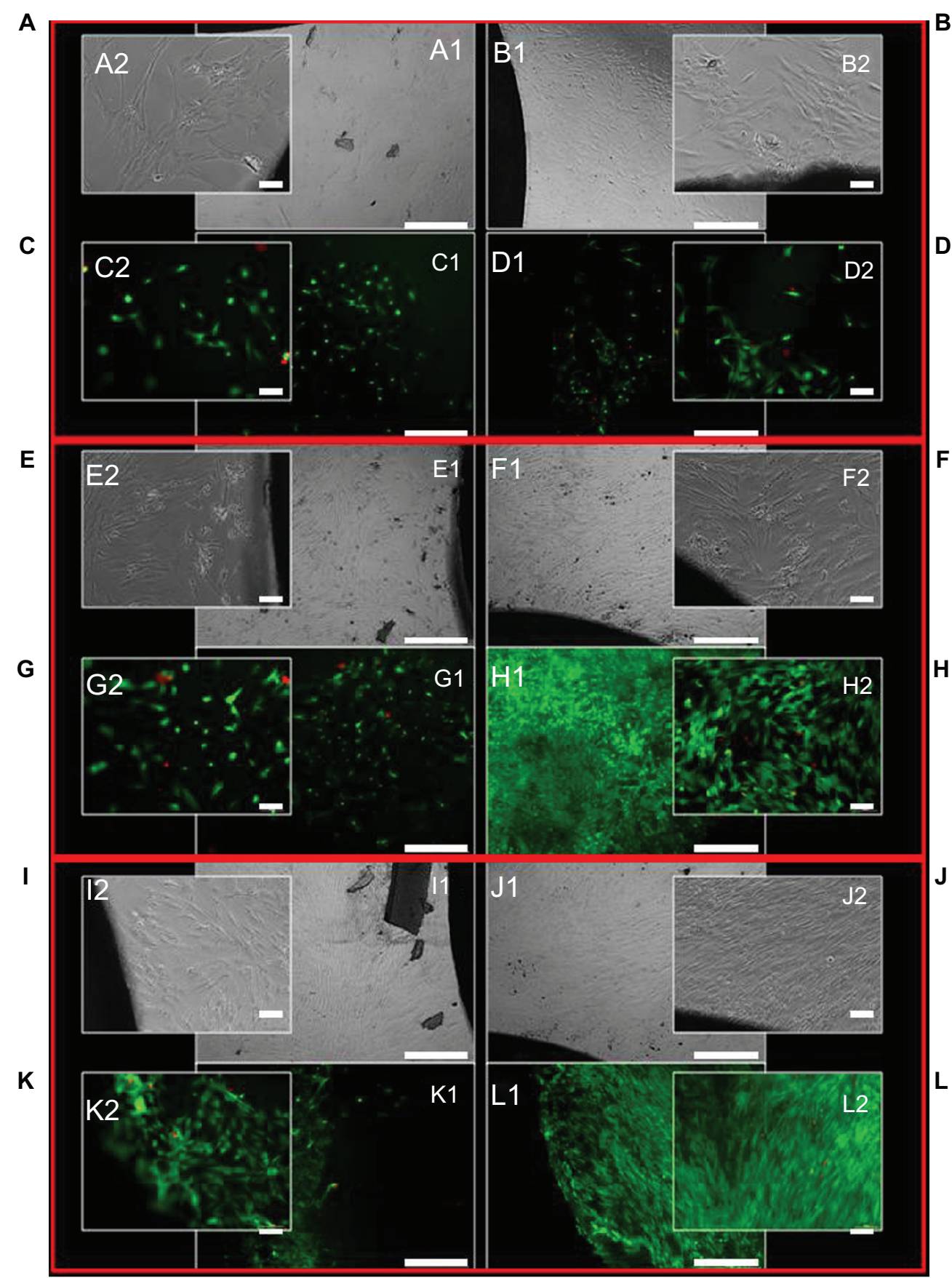

Figure I I Microscopic images of in vitro cell culture on the nanohydroxyapatites surfaces. Images at I (A-D), 7 (E-H), and I4 (I-L) days after changing to an osteoblastic medium; I = 4× magnification (white scale bars $100 \mu \mathrm{m}$ ); 2 = I0× magnification (white scale bars $100 \mu \mathrm{m}$ ). (A, B, E, F, I, and J) Microscopic images from optical microscopy, showing morphology of cells on the surface of the culture plastic next to NanoXIM (Fluidinova, Moreira da Maia, Portugal). (A, E, and I) and GoHAP (B, F, and J) samples. (C, D, G, H, K, and L) Microscopic images from fluorescent microscopy showing morphology of cells on the surface of NanoXIM (C, G, and K) and GoHAP (D, H, and L) after FDA/PI staining.

Abbreviations: FDA, fluorecein diacetate; PI, propidium iodide.

The majority of the cells, although alive (FDA positive), were not flattened on the surface of the sample, and had a low confluence. The control cells (cultured on TCP) were correctly flattened, similar in shape to those visualized on GoHAP (data not shown).
On day 14, a multilayered culture was found on TCP near the GoHAP samples (Figure 11J), while single cells could still be easily identified near the NanoXIM samples. These latter samples showed a low stage of proliferation, but with the correct morphology (Figure 11I). The cells cultured on the surface 
of GoHAP (Figure 11L), similar to those on culture plastic, displayed multilayer growth and were uniformly distributed on the surface of the samples. This observation was confirmed by scanning microcopy (Figure 12A and B). In contrast, on NanoXIM, the cells only partly covered the surface, although only the single cells were dead (PI positive) (Figure 11K). Even though there were significantly fewer cells compared with the GoHAP or TCP control, they were flattened and seemed to adhere to the surface of the sample (Figure 11K).

\section{Quantitative assays in a culture on the biomaterials' surface}

Figure 13 shows the results of the XTT assay and DNA measurements in the population of cells cultured in 96-well culture plates on the surface of the GoHAP and reference NanoXIM samples. The viability assay revealed a population of living cells growing in time on GoHAP (Figure 13A), which correlated well with the increasing amount of DNA (Figure 13B). The absolute values were lower compared to the TCP control at all time points: $21 \%$ on day $2,34 \%$ on day 7 , and $61 \%$ on day 14 in the XTT assay; and $113 \%$ on day $2,56 \%$ on day 7 , and $60 \%$ on day 14 in the PicoGreen test. At the same time, all of the results obtained for GoHAP were substantially higher compared to the results for NanoXIM, which served as a reference nanohydroxyapatite. In this case, the highest values in both the XTT and PicoGreen assays were obtained on Day 14 and did not exceed $5 \%$ and $4 \%$ of the TCP control, respectively.

\section{Biocompatibility examination in an extract from the tested biomaterials}

Figure 14 presents the results of the standard cytocompatibility study based on the cells' response toward the materials' extracts.
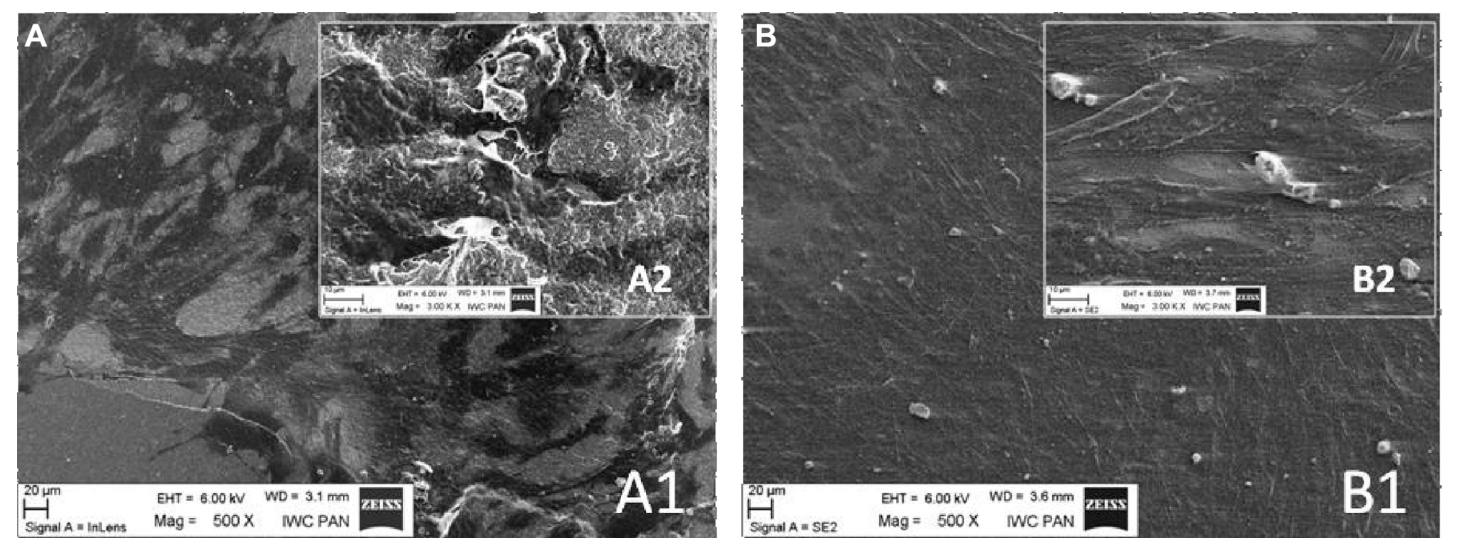

Figure 12 SEM micrographs of in vitro cell culture on the nanohydroxyapatites surfaces 14 days after changing to osteoblastic medium. Morphology of cells on the surface of (A) NanoXIM (Fluidinova, Moreira da Maia, Portugal) and (B) GoHAP. I = 500× magnification (black scale bars $20 \mu \mathrm{m}$ ); $2=3000 \times($ black scale bars I0 $\mu \mathrm{m}$ ). Abbreviation: SEM, scanning electron microscopy. 
A

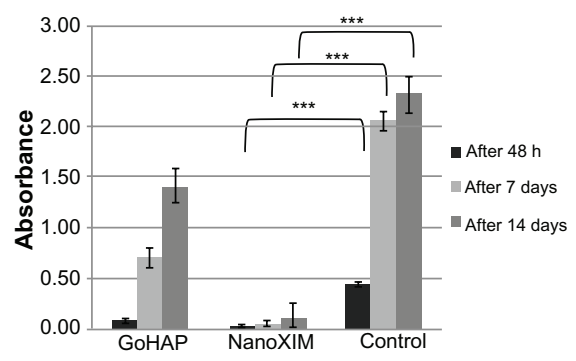

B

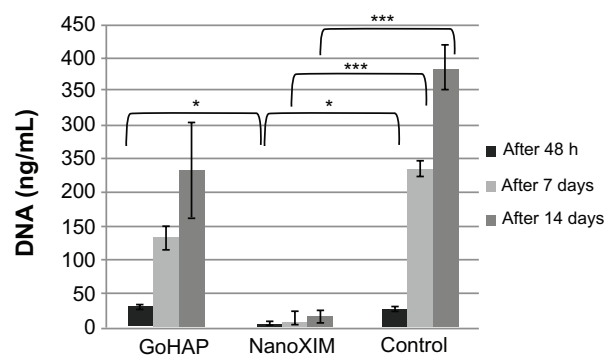

Figure 13 Representative results of (A) XTT assay and (B) DNA assay for GoHAP, NanoXIM (Fluidinova, Moreira da Maia, Portugal), and TCP (control, plastic surface) at three different time points (I, 7, and I4 days after changing to osteoblastic medium).

Note: Data presented as mean \pm SD.

Abbreviations: TCP, tissue-culture polystyrene; SD, standard deviation; XTT, 2,3-bis-(2-methoxy-4-nitro-5-sulfophenyl)-2H-tetrazolium-5-carboxanilide.

\section{Discussion}

By implementing a microwave heating technology with very high energy density, a method of HAp nanopowder synthesis was developed, which resulted in a material that mimics natural bone apatite. It was a pure, hexagonal non-stoichiometric HAp with a plate-like morphology, an average grain size of $6 \mathrm{~nm}$, and SSA over $200 \mathrm{~m}^{2} / \mathrm{g}$. As this powder had both a small particle size much lower than $10 \mathrm{~nm}$ and a nonstoichiometric $\mathrm{Ca} / \mathrm{P}$ molar ratio equal to 1.57 , it achieved a high degradation rate and high biocompatibility. It was visible during the degradation test conducted for GoHAP and NanoXIM. GoHAP with a grain size of $6 \mathrm{~nm}$ and a $\mathrm{Ca} / \mathrm{P}$ molar ratio of 1.57 had almost 5 times larger solubility than commercial nanopowder with an average grain size of $17 \mathrm{~nm}$ and a $\mathrm{Ca} / \mathrm{P}$ molar ratio of 1.67. Furthermore, the
A

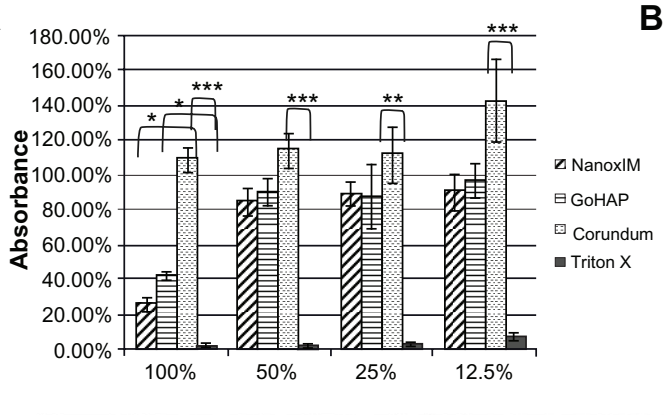

B

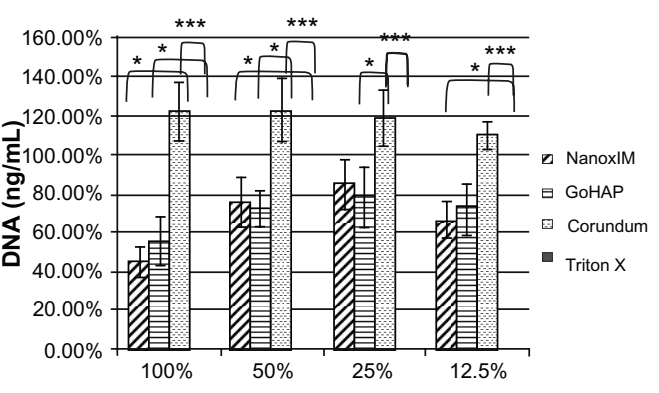

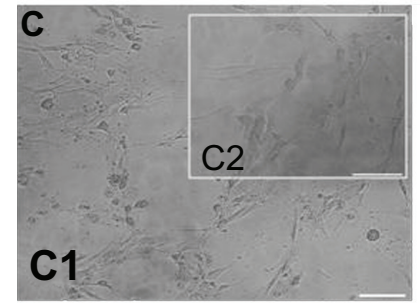

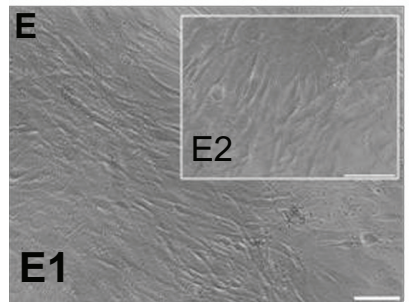

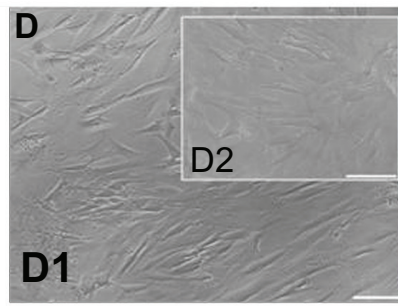

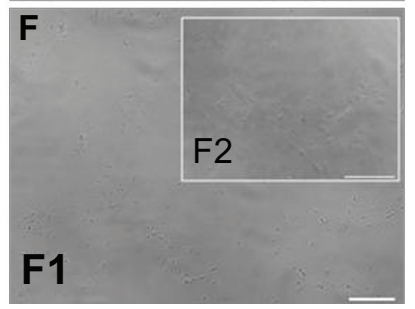

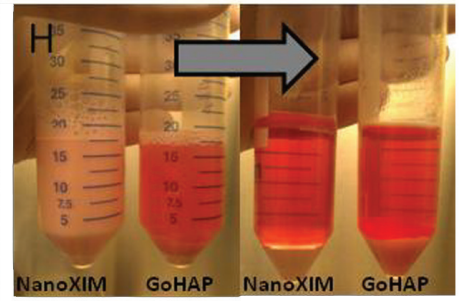

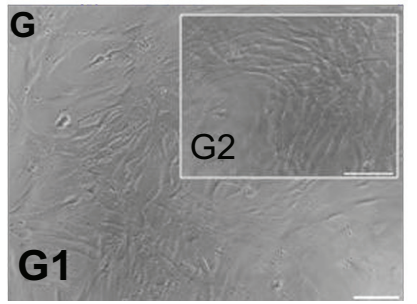

Figure 14 Biocompatibility examination in an extract of tested biomaterials. Representative results of (A) XTT assay and (B) DNA assay in four different dilutions of extracts $(100 \%, 50 \%, 25 \%, 12.5 \%$, and $6.25 \%)$ for both nanohydroxyapatites and positive (triton $\mathrm{X}$ ) and negative $\left(\mathrm{Al}_{2} \mathrm{O}_{3}\right.$, corundum) control. Results compared with the viability of cells cultured in medium, which was defined as $100 \%$, and presented as mean \pm SD. (C-G) Morphology evaluation of cells cultured in the presence of extracts from nanopowders at a concentration of $50 \mathrm{mg} / \mathrm{mL}$ of suspension $100 \%$ of extract. Optical microscopic images representative photos: I = $4 \times($ white scale bars $100 \mu \mathrm{m}) ; 2=10 \times($ white scale bars $100 \mu \mathrm{m}$ ). (C) NanoXIM (Fluidinova, Moreira da Maia, Portugal); (D) GoHAP; (E) corundum; (F) triton X; (G) TCP (control, plastic surface); (H) extracts from nanopowders (GoHAP, NanoXIM) before and after centrifugation.

Abbreviations: SD, standard deviation; TCP, tissue-culture polystyrene; XTT, 2,3-bis-(2-methoxy-4-nitro-5-sulfophenyl)-2H-tetrazolium-5-carboxanilide. 
literature shows that osteoblast adhesion is strongly driven by the material surface size: a decrease in particle size increases the osteoblast adhesion which is directly related to the larger surface area, seen in this paper by comparing NanoXIM (with a surface close to $120 \mathrm{~m}^{2} / \mathrm{g}$ ) to GoHAP (with an SSA almost twice as large, equal to $236 \mathrm{~m}^{2} / \mathrm{g}$ in in vitro studies). ${ }^{12}$ At all time points the cell culture on GoHAP had superior results, showing a multilayer cell culture with correct morphology over the entire material surface. Annealing of GoHAP powder at a temperature of $375^{\circ} \mathrm{C}$ decreased significantly the degradation rate. It seems that the advantages for the possible application of GoHAP nanoparticles for the development of resorbable bone scaffolds are lost when the material undergoes the first thermal transformation at $375^{\circ} \mathrm{C}$.

The application of microwaves enabled a precise control of the crucial process parameters: time and pressure, and ensured high purity of the reaction conditions. Compared to conventional heating, microwaves transmit energy directly to the entire volume of reaction media. The rapid heating process leads to overheating of the solution and precipitation of nanocrystals with a nonequilibrium structure, similar to those produced in the human body, and reduces temperature gradients, which allows us to obtain a uniform nano-grain size distribution. The process is as short as 90 seconds and subsequently the solution is rapidly cooled, so that no secondary grain growth takes place..$^{18,39}$

\section{Conclusion}

A highly biocompatible HAp nanopowder, which we called GoHAP, was successfully synthesized using a novel method in which heating was accomplished with high density microwave radiation in a closed vessel. This allowed for a unique material to be produced inexpensively with an easily scalable method. The obtained nanopowder had unique properties; it was a pure, fully crystalline HAp nanopowder with a hexagonal structure. Its grains had needle-like morphology, an SSA close to $240 \mathrm{~m}^{2} / \mathrm{g}$, a Ca/P molar ratio of 1.57 , and an average particle size (estimated using TEM) under $6 \mathrm{~nm}$. As the degradation study demonstrated in conditions simulating the human body, its solubility was 5 times larger than that of commercial nanopowder (NanoXIM). These properties were lost when the powder was heated to the thermal transformation temperature of $375^{\circ} \mathrm{C}$, at which point its structure became dehydrated and the material's solubility matched that of the commercial nanopowder. GoHAP showed excellent biocompatibility properties, as confirmed by in vitro tests. Its properties were good not only as a surface for cell growth (which was demonstrated by FDA/ PI staining and the XTT results) as no vacuolization or cell membrane lysis was found on the surface, but it also promoted cell proliferation as confirmed by the results of a DNA assay. The cells were equally distributed along the available ground surface, building a single confluent layer. Furthermore, the cells presented a correctly flattened phenotype, maintaining a morphology typical for bone cells.

The presented results were achieved due to an extremely short synthesis time with high energy delivered to the reactants using a unique microwave reactor. With its unique features, the obtained GoHAP nanopowder is a promising material for resorbable bone implant fabrication.

\section{Acknowledgments}

This study was conducted at the Institute of High Pressure Physics, Polish Academy of Science (PAS). This work was financed by the European Regional Development Fund within the Innovative Economy Operational Programme in the frame of BIO-IMPLANT project - "Bioimplants for the treatment of bone tissue lesions in oncological patients" (POIG.01.01.02-00-022/09); the SONOSCA project financed by the European Union, Sixth Framework Programme for research and development; and the Polish Ministry of Science and Higher Education: Grant NN507 469 937. The research was carried out with the use of CePT infrastructure financed by the European Union - the European Regional development Fund within the Operational Programme "Innovative Economy" for 2007-2013. The authors would like also to thank: S Gierlotka, J Mizeracki, and A Presz from the Institute of High Pressure Physics PAS, P Dluzewski and K Sobczak from the Institute of Physics PAS, A Karas from the Institute of Electronic Materials Technology, Professor Andrzej Gorecki and Dr Marcin Kowalski from the Department of Orthopedics and Traumatology, Medical University of Warsaw.

\section{Disclosure}

The authors report no conflicts of interest in this work.

\section{References}

1. Porter JR, Ruckh TT, Popat KC. Bone tissue engineering: a review in bone biomimetics and drug delivery strategies. Biotechnol Prog. 2009;25(6):1539-1560.

2. European Technology Platform Nanomedicine. Roadmaps in Nanomedicine Towards 2020. European Technology Platform Nanomedicine; 2009. Available from: http://www.etp-nanomedicine.eu/public/pressdocuments/publications/etpn-publications/091022_ETPN_Report_2009. pdf. Accessed December 12, 2012.

3. Barrère F, van Blitterswijk CA, de Groot K. Bone regeneration: molecular and cellular interactions with calcium phosphate ceramics. Int J Nanomedicine. 2006;1(3):317-332.

4. Zhang R, Ma PX. Poly(alpha-hydroxyl acids)/hydroxyapatite porous composites for bone-tissue engineering. I. Preparation and morphology. J Biomed Mater Res. 1999;44(4):446-455. 
5. Li SH, De Wijn JR, Layrolle P, de Groot K. Synthesis of macroporous hydroxyapatite scaffolds for bone tissue engineering. J Biomed Mater Res. 2002;61(1):109-120.

6. Flautre B, Descamps M, Delecourt C, Blary MC, Hardouin P. Porous HA ceramic for bone replacement: role of the pores and interconnections - experimental study in the rabbit. J Mater Sci Mater Med. 2001;12(8):679-682.

7. Kim SS, Sun Park M, Jeon O, Yong Choi C, Kim BS. Poly(lactideco-glycolide)/hydroxyapatite composite scaffold for bone tissue engineering. Biomaterials. 2006;27(8):1399-1409.

8. Ginebra MP, Fernández E, Driessens FCM, Planell JA. Modeling of the hydrolysis of $\alpha$-tricalcium phosphate. J Am Ceram Soc. 1999;82(10):2808-2812.

9. Meyer JL, Fowler BO. Lattice defects in nonstoichiometric calcium hydroxyapatites. A chemical approach. Inorg Chem. 1982;21: 3029-3035.

10. Dingreville R, Qu J, Cherkaoui M. Surface free energy and its effects on the elastic behavior of nano-sized particles, wires and films. $J$ Mech Phys Solids. 2005;53(8):1827-1854.

11. Fischer FD, Waitz T, Vollath D, Simha NK. On the role of surface energy and surface stress in phase-transforming nanoparticles. Prog Mater Sci. 2008;53(3):481-527.

12. Webster TJ, Siegel RW, Bizios R. Osteoblast adhesion on nanophase ceramics. Biomaterials. 1999;20(13):1221-1227.

13. Suchanek WL, Shuk P, Byrappa K, Riman RE, TenHuisen KS, Janas VF. Mechanochemical-hydrothermal synthesis of carbonated apatite powders at room temperature. Biomaterials. 2002;23(3):699-710.

14. Choi D, Kumta PN. An alternative chemical route for synthesis and thermal stability of chemically enriched hydroxyapatite. J Am Ceram Soc. 2006;89(2):444-449.

15. Kalita SJ, Verma S. Nanocrystalline hydroxyapatite bioceramic using microwave radiation: Synthesis and characterization. Mater Sci Eng C. 2010;30(2):295-303.

16. Uota M, Arakawa H, Kitamura N, Yoshimura T, Tanaka J, Kijima T. Synthesis of high surface area hydroxyapatite nanoparticels by mixed surfactant-mediated approach. Langmuir. 2005;21(10):4724-4728.

17. Clark DE, Sutton WH. Microwave processing of materials. Аnпи Rev Mater Sci. 1996;26:299-331.

18. Leonelli C, Lojkowski W. Main development directions in the application of microwave irradiation to the synthesis of nanopowders. Chim Oggi. 2008;26(1):26-29.

19. Khollam YB, Deshpande AS, Patil AJ, Potdar HS, Deshpande SB, Date SK. Microwave-hydrothermal synthesis of equi-axed and submicron-sized BaTiO3 powders. Mater Chem Phys. 2001;71(3): 304-308.

20. Yang H, Huang C, Li X, Shi R, Zhang K. Luminescent and photocatalytic properties of cadmium sulfide nanoparticels synthesized via microwave irradiation. Mater Chem Phys. 2005;90(1):155-158.

21. Smolen D, Lojkowski W, Chudoba T, Kedzierska A, Swieszkowski W; Institute of High Pressure Physics, Polish Academy of Sciences. The method of nanoplates obtaining from synthetic hydroxyapatite and method of nanopowder with nanoplates obtaining from synthetic hydroxyapatite. Polish Patent Application P-369906. 2011 Dec 15.

22. School of Physics - Software: Program DBWS-9807a [webpage on the Internet]. Atlanta, GA: School of Physics. Available from: http://www. ccp14.ac.uk/ccp/web-mirrors/dbws/downloads/young/download_dbws. html. Accessed September 3, 2012.
23. Wejrzanowski T, Pielaszek R, Opalinska A, Matysiak H, Lojkowski W, Kurzydlowski KJ. Quantitative methods for nanopowder characterization. Appl Surf Sci. 2006;253(1):204-208.

24. Gallagher JA, Gundle R, Beresford JN. Isolation and culture of bone-forming cells (osteoblasts) from bone. Methods Mol Med. 1996;2:233-262.

25. Kudelska-Mazur D, Lewandowska-Szumiel M, Benke G, Kowalski M, Komender J. Isolation of human primary osteoblasts for biomaterials investigation in vitro. Eng Biomater. 2001;15/16:51-58.

26. Franceschi RT, Young J. Regulation of alkaline phosphatase by 1,25dihydroxyvitamin D3 and ascorbic acid in bone-derived cells. $J$ Bone Miner Res. 1990;5(11):1157-1167.

27. Scudiero DA, Shoemaker RH, Paull KD, et al. Evaluation of a soluble tetrazolium/formazan assay for cell growth and drug sensitivity in culture using human and other tumor cell lines. Cancer Res. 1988;48(17):4827-4833.

28. Newell DG, editor. Core Techniques Cell and Tissue Culture: Laboratory Procedures. New York: Wiley; 1996.

29. International Organization for Standardization. Biological evaluation of medical devices - Part 5: Tests for in vitro cytotoxicity. ISO 109935:2009.

30. Chroscicka A, Wozniak P, Olkowski R, et al. Human bone derived cells in contact with alumina ceramics - preliminary studies. In: Lekszycki T, Maldyk P, editors. Advanced Course on Biomaterials. BMAT: Warsaw; 2005:9-30.

31. Kitamura S, Ohgushi H, Hirose M, Funaoka H, Takakura Y, Ito H. Osteogenic differentiation of human bone marrow derived mesenchymal cells cultured on alumina ceramics. Artif Organs. 2004;28(1):72-82.

32. Brown PW, Constantz B. Hydroxyapatite and Related Materials. Boca Raton: CRC Press; 1994

33. Chang J, Johnson E. Surface and bulk melting of small metal clusters. Philos Mag. 2005;85:3617-3627.

34. Sudarsanan K, Young RA. Significant precision in crystal structural details. Holly springs hydroxyapatite. Acta Crystallogr B. 1969;25(8): 1534-1543.

35. Shu C, Yanwei W, Hong L, Zhengzheng P, Kangde Y. Synthesis of carbonated hydroxyapatite nanofibers by mechanochemical methods. Cer Int. 2005;31(1):135-138.

36. Jovanovica J, Adnadjevicb B, Kicanovicc M, Uskokovica D. The influence of hydroxyapatite modification on the cross-linking of polydimethylsiloxane/HAp composites. Colloids Surf B Biointerfaces. 2004;39(4):181-186.

37. Takahashi H, Yashima M, Kakihana M, Yoshimura M. A differential scanning calorimeter study of the monoclinic (P21/b. \$ hexagonal $(\mathrm{P} 63 / \mathrm{m})$ reversible phase transition in hydroxyapatite. Thermochimica Acta. 2001;371(1-2):53-56.

38. Islam M, Mishra PC, Patel R. Physicochemical characterization of hydroxyapatite and its application towards removal of nitrate from water. J Environ Manage. 2010;91(9):1883-1891.

39. Perreux L, Loupy A. A tentative rationalization of microwave effects in organic synthesis according to the reaction medium, and mechanistic considerations. Tetrahedron. 2001;57(45):9199-9223.
International Journal of Nanomedicine

\section{Publish your work in this journal}

The International Journal of Nanomedicine is an international, peerreviewed journal focusing on the application of nanotechnology in diagnostics, therapeutics, and drug delivery systems throughout the biomedical field. This journal is indexed on PubMed Central, MedLine, CAS, SciSearch ${ }^{\circledR}$, Current Contents ${ }^{\circledR} /$ Clinical Medicine,

\section{Dovepress}

Journal Citation Reports/Science Edition, EMBase, Scopus and the Elsevier Bibliographic databases. The manuscript management system is completely online and includes a very quick and fair peer-review system, which is all easy to use. Visit http://www.dovepress.com/ testimonials.php to read real quotes from published authors. 